\title{
Parameter analysis of wind-induced vibration of electrical transmission line models
}

\author{
YOU Yi ${ }^{1}$, ZHAO Shuang ${ }^{2, a}$, LI Wensheng ${ }^{1}$ and HE Cheng ${ }^{1}$ \\ ${ }^{1}$ Electric Power Company of State Grid of China in xinjiang, Electric Power Research Institute , \\ Urumqi 830011, PR China \\ ${ }^{2}$ School of Civil Engineering, Chongqing University, Chongqing 400045, PR China \\ a644621771@qq.com
}

\begin{abstract}
Keywords: parameter analysis, finite element models, electrical transmission lines, wind-induced vibration

Abstract. there are distinct growing tendencies in the span and height of electrical transmissions lines. However, little attention was paid on parameter analysis of wind-induced vibration of electrical transmission lines, especially on the gradient height. By means of a finite element software, electrical transmission line models were established to study the influence of 4 parameters to the response of electical conductors and the gust response factor through a simulated wind field. The influence of some parameter was nonlinear and irregular.
\end{abstract}

\section{Introduction}

Due to the disequilibrium in the resource distribution, electrical transmission lines, which have traits of ultra-high-voltage, long span and large density, will play an important role in the economic advancement.

Ozono et $\mathrm{al}^{[1]}$ have studied the vibration properties of an electrical transmission tower-line system in plane. Yasui ${ }^{[2]}$ has established electrical transmission line models and calculated their dynamic characteristics and wind-induced vibration properties by means of link elements. Momomura ${ }^{[3]}$ has measured wind-induced vibration of a full-scale electrical transmission line system in a mountainous area. Loredo-Souza and Davenport ${ }^{[4,5]}$ has come up with design plans of electrical transmission line models in two different scale and studied aerodynamic damping and the interaction of lines between them. Observed in wind tunnel tests of a full aeroelastic model ${ }^{[6,7]}$, the wind-induced responses of the electrical transmission tower-line system in short span are very complicated. The vibration of an electrical transmission tower occurs not only in the along-wind direction, but also the across-wind direction and the torsional direction. Observed in wind tunnel tests of a aeroelastic model ${ }^{[8-14]}$, the wind-induced responses of the electrical transmission tower-line system in long span are more complicated in the effects of coupling between transmission tower and line.

There are distinct growing tendencies in the span and height of electrical transmissions lines. Wind loads is the number one cause for power line damage. Nevertheless, little literature refers to the parameter analysis of wind-induced vibration properties of electrical transmission lines. In default of these analyses, engineering designers cannot search any codes about electrical transmissions lines whose height exceed gradient height hitherto. Under the current conditions, the influence of gradient height only can be studied by numerical simulation. Finally, based on elaborate models and analyses from ANSYS software, the influence trend of different parameter and a corresponding gust response factor $^{[15]}$ can be derived, which benefit engineering requirements in the future.

\section{Wind field simulation}

Through harmonic synthesis method ${ }^{[16,17]}$, the target stochastic wind field can be simulated accurately and effectively. The spectral density associated with stochastic wind velocity and its coherence have the forms suggested by Davenport $(1961)^{[18]}$. The target wind filed is terrain exposure 
categoriy B from China code ${ }^{[19]}$. Due to limited space, some equations can not be listed here. Figs. 1 and 2 respectively show different characteristics of target wind field and simulation wind field.

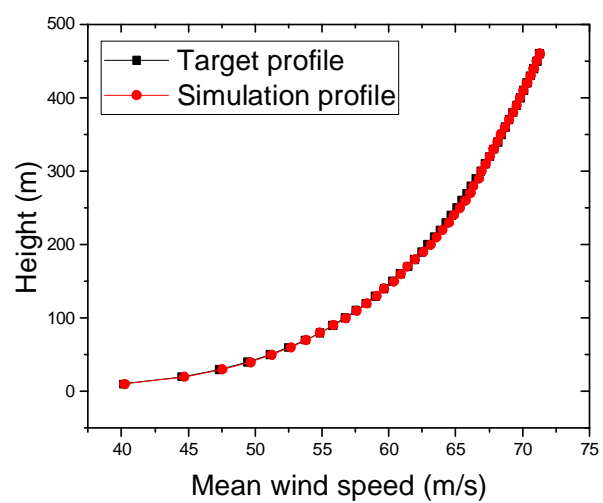

Fig. 1 Target profile VS simulatoin profile

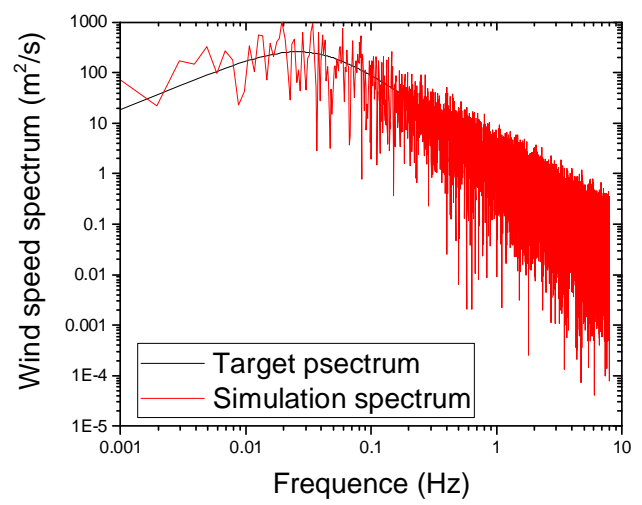

Fig. 2 Target spectrum VS simulatoin spectrum

Figs. 1 and 2 both show the reliability of simulatoin wind filed.

\section{Parameter analysis}

Utilising the ANSYS software, electrical transimission line models with 3 spans was established and it is without any bunched conductor. As for boundary Conditions, one side of every insulator connects an electrical conductor and another side link a fixed hinge support. In the light of past study, the influence of coupling between transmission tower and line is negligible to the transmission line. Hence, this electrical transimission line model is valid. Fig. 3 shows the ANSYS model of the electrical conductor mentioned above.

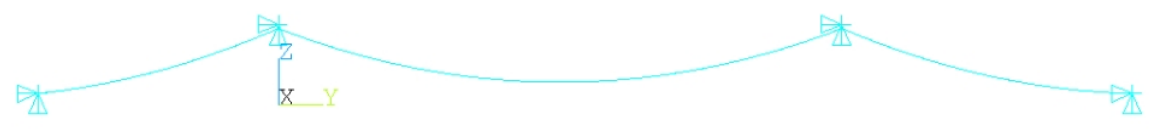

Fig. 3 Model of the electrical conductor

As shown in Fig. 3, obviously, the whole model was symmetric in plan. The middle span was $2500 \mathrm{~m}$ with the ratio of sag to span equalling to $9.458 \%$ and the rest of span were $1200 \mathrm{~m}$ with the ratio of sag to span equalling to $4.268 \%$. The length of insulator was $19 \mathrm{~m}$ and the height of the middle insulator top was $350 \mathrm{~m}$. The default of average wind speeds was $40 \mathrm{~m} / \mathrm{s}$ in the $10 \mathrm{~m}$ height. Through ANSYS models, the effects that 4 mutual independent parametres ( wind speed, span, height and mass ) lead to diffenent wind-induced vibration properties of electrical transimission lines can be studied. Attention is put on the tension induced only by wind loads, in the end of the middle span, and displacement in the along-wind direction, in the midst of the middle span, of electical transimission lines. The Gust response factor is derived by dividing the max of tension by its average.

Fig. $4,6,8$ and 10 respectively show the influence of mean wind speed, span, height of the middle insulator top and multiple of mass of electrical conductors to displacement in the along-wind direction. Fig. 5,7,9 and 11 respectively show the influence of the 4 parameters mentioned above to tension of a middle electrical conductor in the end of the middle span.

Table 1-4 respectively show the influence of the 4 parameters mentioned above to the gust response factor.

\section{(1) Wind velocity}

The variable of average wind speeds in the $10 \mathrm{~m}$ height ranged from $20 \mathrm{~m} / \mathrm{s}$ to $40 \mathrm{~m} / \mathrm{s}$ and the increment was $5 \mathrm{~m} / \mathrm{s}$. 

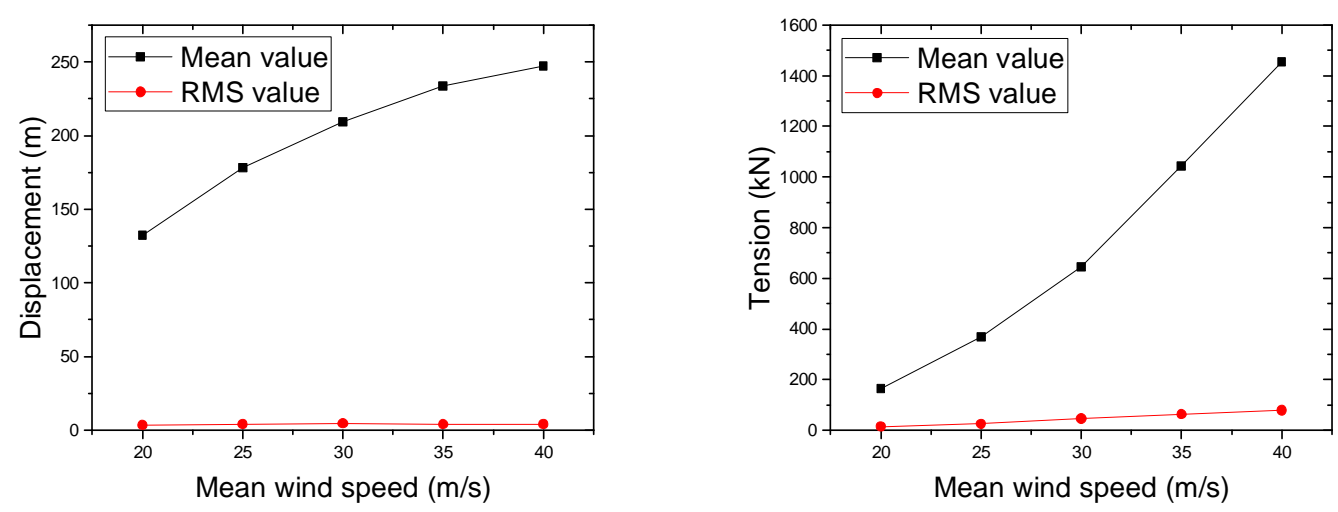

Fig. 4 The influence of mean wind speed to displacement Fig. 5 The influence of mean wind speed to tension

Table 1 The influence of mean wind speed to the gust response factor

\section{(2) Span}

\begin{tabular}{|c|c|c|c|c|c|}
\hline Mean wind speed $(\mathrm{m} / \mathrm{s})$ & 20 & 25 & 30 & 35 & 40 \\
\hline Gust response factor & 1.265 & 1.195 & 1.208 & 1.23 & 1.145 \\
\hline
\end{tabular}

The variable of span ranged from $500 \mathrm{~m}$ to $2500 \mathrm{~m}$ with the constant of the ratio of sag to span and the increment was $50 \mathrm{~m}$ and the increment was $500 \mathrm{~m}$.

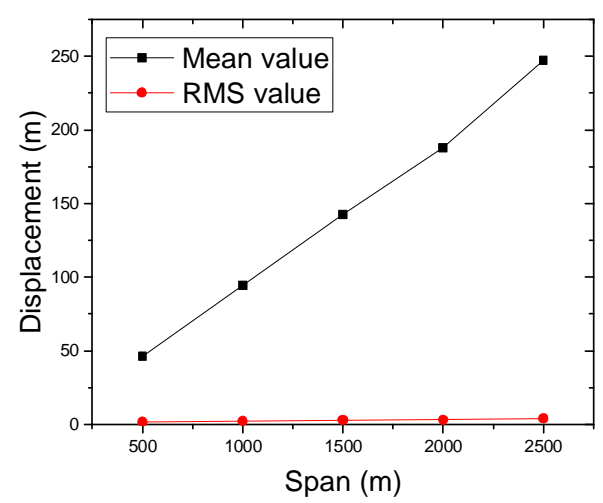

Fig. 6 The influence of span to displacement

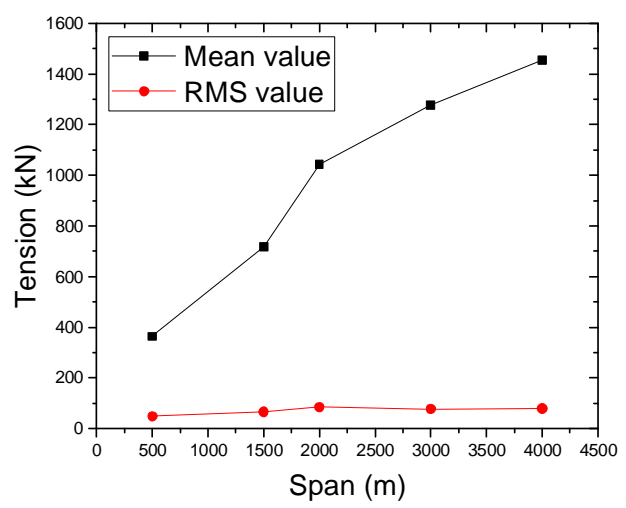

Fig. 7 The influence of span to tension

Table 2 The influence of span to the gust response factor

\section{(3) Height}

\begin{tabular}{|c|c|c|c|c|c|}
\hline Span $(\mathrm{m})$ & 500 & 1000 & 1500 & 2000 & 2500 \\
\hline Gust response factor & 1.346 & 1.276 & 1.171 & 1.153 & 1.145 \\
\hline
\end{tabular}

The variable of height of insulator top ranged from $350 \mathrm{~m}$ to $500 \mathrm{~m}$. Besides, gradient height $(350 \mathrm{~m})$ was considered.

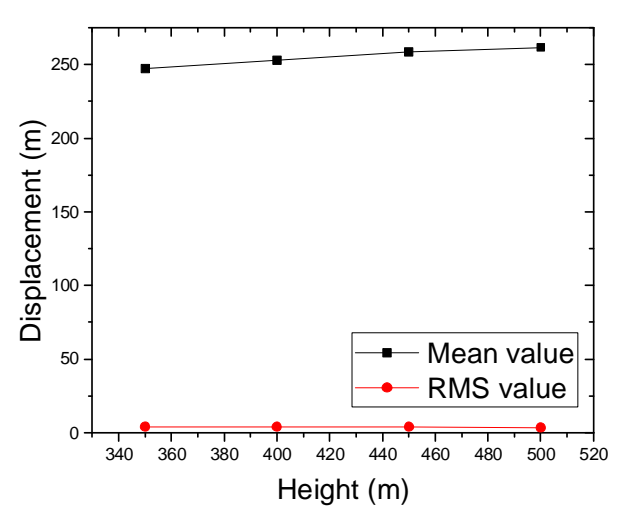

Fig. 8 The influence of height to displacement

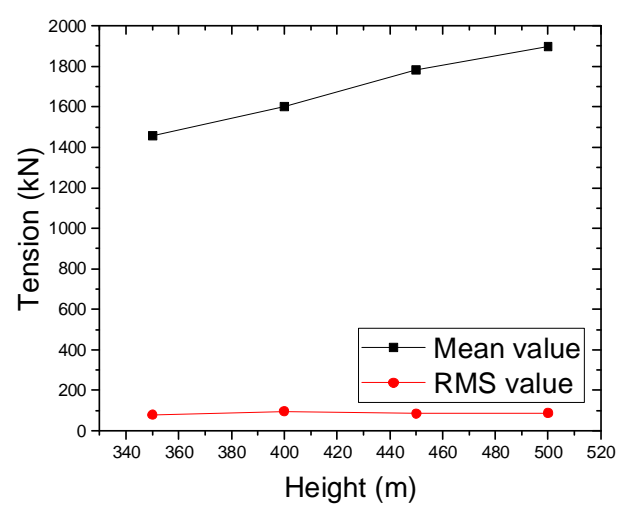

Fig. 9 The influence of height to tension 
Table 3 The influence of height to the gust response factor

\section{(4) Mass}

\begin{tabular}{|c|c|c|c|c|}
\hline Height $(\mathrm{m})$ & 350 & 400 & 450 & 500 \\
\hline Gust response factor & 1.145 & 1.163 & 1.128 & 1.124 \\
\hline
\end{tabular}

The variable of the multiple of the original electical conductor mass ranged from 1 to 5 and the increment was 1 .
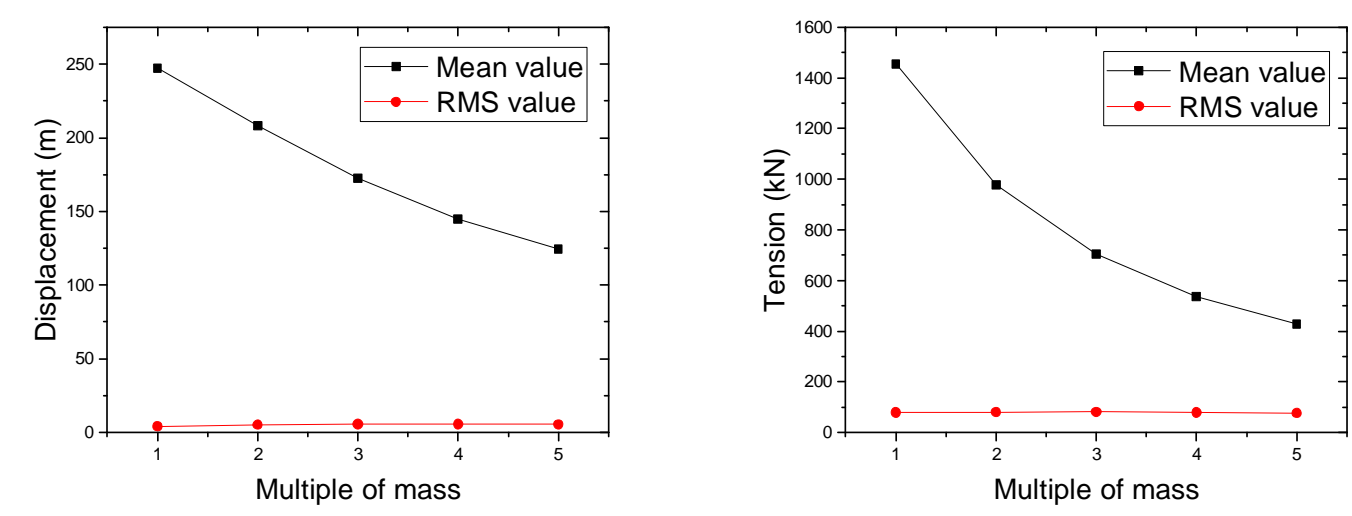

Fig. 10 The influence of multiple of mass to displacement Fig. 11 The influence of multiple of mass to tension

Table 4 The influence of multiple of mass to the gust response factor

\begin{tabular}{|c|c|c|c|c|c|}
\hline Multiple of mass & 1 & 2 & 3 & 4 & 5 \\
\hline Gust response factor & 1.145 & 1.219 & 1.328 & 1.393 & 1.503 \\
\hline
\end{tabular}

\section{Conclusions}

(1) The RMS values of the response of the measured electical conductor were negligible for the corresponding mean value. The response of the measured electical conductor was quasi static.

(2) With the multiple of mass increasing, the response of the measured electical conductor decreased. However, it was converse to the rest of variables.

(3) The influence of distance parameters to the response of the measured electical conductor approximated linear change. However, it was nonlinear to the rest of variables.

(4) The influence of mean wind velocity to the gust response factor was irregular. With span increasing, the gust response factor decreased. However, it was converse to multiple of mass. In addition, below gradient height, With height increasing, the gust response factor increased, but, upon gradient height, it was converse.

\section{Acknowledgements}

This work was financially supported by the Natural Science Foundation of China (51478069).

\section{References}

[1] Shigehira Ozono, Junji Maeda. In-plane dynamic interaction between a tower and conductors at lower frequencies [ J ] .Engineering Structures,1992, 14 (4) : 210- 216.

[2] Yasui H, Marukawa H, Momomura Y, et al. Analytical study on wind-induced vibration of power transmission towers [ J ] .Journal of Wind Engineering and Industrial Aerodynamics, 1999, 83 : 431441. 
[3] Momomura Y , Marukawa H , Okamura T , et al . Full-scale measurements of wind-induced vibration of a transmission line system in a mountainous area $[\mathrm{J}]$. Journal of Wind Engineering and Industrial Aerodynamics , $1997,72: 241-252$.

[4] A.M. Loredo-Souza, A.G. Davenport.A novel approach for wind tunnel modeling of transmission lines [J].Journal of Wind Engineering and Industrial Aerodynamics, 2001,89(14):1017-1029. [5] A.M. Loredo-Souza, A.G. Davenport.Wind tunnel aeroelastic studies on the behaviour of two parallel cables [J].Journal of Wind Engineering and Industrial Aerodynamics, 2002,90:407-414.

[6] Lou Wenjuan, Sun Bingnan , Tan Jinchun . Wind tunnel test and numerical computation on wind-induced vibration for tall lattice tower [J] . Journal of Vibration Engineering , $1996,9(3)$ : 318-322 .

[7] WANG Shi-cun, SUN Bing-nan, LOU Wen-juan et al . Wind tunnel test and theoretical analysis on aeroelastic model of single-rod transmission tower $[\mathrm{J}]$. Journal of Zhejiang University(Engineering Science), $2005,1: 87-91$.

[8] LI Zheng-liang , XIAO Zheng-zhi , HAN Feng et al . Aeroelastic Model Design and Wind Tunnel Tests of 1000 kV Hanjiang Long Span Transmission Line System [J] . Power System Technology, 2008, 32 ( 12 ) : 1-5.

[9] DENG Hong- zhou , ZHU Song- ye , CHEN Xiao- ming et al . Wind tunnel test on aeroelastic model of long span transmission line system [J] . JOURNAL OF TONGJI UNIVERSITY , 2003 , 31(2) : 132-137.

[10] DENG Hong- zhou , ZHU Song- ye , WANG Zhao-min et al . Wind Tunel Investigation on Wind-induced Vibration Control of Long Span Transmission Line Systems [J] . JOURNAL OF TONGJI UNIVERSITY , $2003,31(9): 1019-1013$.

[11] Guo Yong. Studies on Wind-induced Dynamic Response and Vibration Control of Long Span Transmission Line System [D].Zhejiang : College of Civil Engineering and Architecture of Zhejiang University,2006:1-122.

[12] GUO Yong, SUN Bing- nan et al . Wind tunnel test on aeroelastic model of long span transmission line system [J]. Journal of Zhejiang University , 2007 , 41 (9): 1483-1486.

[13] GUO Yong, SUN Bing- nan et al . Time-domain analysis on wind-induced dynamic response of long span power transmission line systems [J]. CHINA CIVIL ENGINEERING JOURNAL , 2006 , 32 (12): 12-17.

[14] GUO Yong, SUN Bing- nan et al . Frequence-domain analysis on wind-induced dynamic response of long span power transmission line systems and vibration control [J]. ACTA AERODYNAMICA SINICA , 2009 , 27(3): 288-294.

[15] J.D. Holmes.Along-wind response of lattice towers I. Derivation of expressions for gust response factors [J]. Engineering Structure , 1994 , 16:287-292. 
[16] HAN Feng, XIAO Zheng-zhi, LI Zheng-liang et al . 3D Stochastic Wind Field Simulation of 1000 kV Hanjiang Long Span Transmission Line System [J]. High Voltage Engineering, 2009, 32(5): 999-1004

[17] Rice SO. Mathematical analysis of random noise: selected papers on noise and stochastic process[ M] .New York :Dover Publish Inc, 1954.

[18] Davenport A G . The dependence of wind load upon meteorological parameters [C]. Proceedings of the International Research Seminar on Wind Effects on Building and Structures: Vol 1 .Ottawa, Canada: [ s.n.], 1967: 19-82.

[19] Electric Power Industry Standards of P.R. China. Technical code for the design of tower and pole structures of overhead transmission line DL/T 5154-2012; 2012 (in Chinese). 